\title{
Semantic Relativism, Expressives, and Derogatory Epithets
}

DOI:

10.1080/0020174X.2019.1612778

\section{Document Version}

Accepted author manuscript

Link to publication record in Manchester Research Explorer

\section{Citation for published version (APA):}

Berskyte, J., \& Stevens, G. (2019). Semantic Relativism, Expressives, and Derogatory Epithets. Inquiry. https://doi.org/10.1080/0020174X.2019.1612778

\section{Published in:}

Inquiry

\section{Citing this paper}

Please note that where the full-text provided on Manchester Research Explorer is the Author Accepted Manuscript or Proof version this may differ from the final Published version. If citing, it is advised that you check and use the publisher's definitive version.

\section{General rights}

Copyright and moral rights for the publications made accessible in the Research Explorer are retained by the authors and/or other copyright owners and it is a condition of accessing publications that users recognise and abide by the legal requirements associated with these rights.

\section{Takedown policy}

If you believe that this document breaches copyright please refer to the University of Manchester's Takedown Procedures [http://man.ac.uk/04Y6Bo] or contact uml.scholarlycommunications@manchester.ac.uk providing relevant details, so we can investigate your claim.

\section{OPEN ACCESS}




\title{
Semantic Relativism, Expressives, and Derogatory Epithets
}

\author{
Justina Berskyte and Graham Stevens \\ University of Manchester
}

\begin{abstract}
Semantic relativism maintains that the truth-value of some propositions is sensitive to a judge parameter, facilitating cases whereby a proposition can be true relative to one judge, but false relative to another. Most prominently, semantic relativism has been applied to predicates of personal tastes (PPTs). Recently, Lasersohn $(2007,2017)$ has urged an extension of semantic relativism to terms traditionally construed as expressives including derogatory epithets (e.g. 'asshole') and, more tentatively, expressions like 'damn'. In this paper, we challenge Lasersohn's extension of relativism. Section one gives a background on semantic theories for expressives and on semantic relativism. In section two, we focus on Lasersohn's (2007) account where he attempts to apply relativism to a wider range of expressives. We argue that because PPTs and expressives have fundamentally different semantic functions, the prospects for a relativistic account are slim. Several problems are presented. Our focus is on the perspective sensitivity of expressive content and the phenomenon of projection failure, as both reveal a fundamental disparity between expressives and PPTs.
\end{abstract}

Keywords: semantic relativism; derogatory epithets; expressives; predicates of personal taste. 


\section{Introduction}

Semantic Relativism holds that some propositions are true or false relative to a judge. This allows for cases of faultless disagreement ${ }^{1}$ : a proposition and its negation can both be true on this account because truth is not a monadic property of propositions. $P$ may be true relative to a judge $J_{1}$, while $\sim P$ is true relative to a distinct judge $J_{2}$. Various applications of this semantic theory have been proposed including to cases of future contingents, epistemic modals, and certain sorts of scalar expressions. The most promising application thus far has been to predicates of personal taste (PPTs) like 'fun', 'tasty', 'disgusting', etc. These generate the most intuitive cases of apparent faultless disagreement:
A: Falafels are tasty
B: Falafels are not tasty

If A's utterance is evaluated with respect to a circumstance of evaluation in which A is the judge, and B's utterance is evaluated with respect to a circumstance of evaluation in which $B$ is the judge, both utterances can be true. Furthermore, it seems plausible that this is the right result - an individual's claim regarding the tastiness of Falafels is surely validated by their assessment of that tastiness, not by the assessment of anybody else.

In recent work, Peter Lasersohn has defended the view that some expressive terms are suitable candidates for a relativist analysis by virtue of their similarity to PPTs. In this paper, we will argue this is mistaken. While there is much to commend in the relativist analysis of PPTs, expressives differ from PPTs in fundamental ways which make a relativist semantics inappropriate for their analysis. We will begin by providing some background on expressives and on relativism in section 1. In section 2, we turn to Lasersohn's more ambitious (2007) attempt to apply a relativist semantics to expressive content more widely. We present a number of arguments to

\footnotetext{
1 The phrase 'faultless disagreement' appears to first be coined by Kölbel (2004) and has been widely discussed since. For helpful discussion see Hu (2018), MacFarlane (2014) and Palmira (2015).
} 
show that there is a fundamental difference in the role that a judge parameter must be invoked for in the explanation of expressive content compared to the role it plays in relativism. Expressive content, we argue, is intrinsically sensitive to the perspective of the judge in a way that makes it highly context-sensitive, whereas the role of the judge parameter in relativism is to explain how different truth evaluations can apply to the same content.

\section{Expressive Content and Semantic Relativism}

Expressives are words or phrases that encode an emotional attitude towards an object, person or an event. Paradigmatically the attitude encoded is that of the speaker, although we will see below that there are important exceptions. Expressives include pure expressives ('damn', 'ouch', 'fuck'), derogatory epithets ('bastards', 'asshole', 'jerk'), as well as racial and other group-targeting slurs. In the first part of this section, we will consider the leading semantic theory of expressives, proposed by Christopher Potts (2007a, 2007b). We then outline Lasersohn's $(2007,2017)$ relativist proposal for at least some of these terms. ${ }^{2}$

\section{1: Potts and Expressives}

Potts $(2007 a)^{3}$ develops a semantic theory for expressives which extends the formal semantic theory, familiar to readers of Kaplan (1989), for indexicals by adding as a parameter of context a judge parameter and an expressive index parameter. A context of utterance is a sequence $c=\left\langle c_{A}, c_{T}, c_{W} c_{J}, c_{\varepsilon}\right\rangle$, where $c_{A}$ is the agent (speaker) of $c$, $c_{T}$ is the time of $c, c_{W}$ is the world of $c, c_{J}$ is the judge of $c$, and $c_{\varepsilon}$ is a set of expressive indices (ibid.: 184). The judge parameter is required for cases where an utterance

\footnotetext{
${ }^{2}$ Which terms, exactly, Lasersohn envisages a relativist semantics for is not entirely clear. In his (2017) he only suggests it for derogatory epithets, although in his (2007) he considers it as a wider analysis of expressives. There is a connected question of which grammatical forms he wishes to apply the analysis to. PPTs are paradigmatically predicates formed from adjectives (is fun, etc.), whereas derogatory epithets are usually nouns/noun phrases (a jerk, the bastard, that asshole, etc.). We include examples using both adjectives and noun phrases.

${ }^{3}$ Potts's original theory is embedded in a wider context of conventional implicatures (Potts (2005)), however the relevant material for this paper only concerns (2007a, 2007b) therefore we will not be discussing his account of conventional implicatures.
} 
appears to encode an expressive attitude distinct from the speaker's. We will consider such cases in detail below, but for now we will give the following, much discussed, example from Kratzer (1999) to illustrate the phenomenon Potts has in mind:

My father screamed that he would never allow me to marry that bastard Webster.

The natural reading of this report is that the expressive attitude encoded by the derogatory epithet 'that bastard' is the attitude of the father of the speaker, rather than the speaker herself. Such cases motivate the introduction of a judge parameter which can, though standardly will not, take a different value to the agent parameter. The semantic contribution of an expressive in a context $c$ is its determination of the parametric setting for $c_{\varepsilon}$ in $c$. This setting is determined by the judge's emotional state, as communicated by the expressive term. For example, normally the term 'bastard' will communicate a greater emotional state and negative attitude towards its object than the term ' git'.

The expressive index is a triple of $\langle a \mathbf{I} b>$, where $a$ is an individual, $b$ is some kind of entity (individual, object or state of affairs) that $a$ stands in an emotional relation to. $\mathbf{I}$ is an interval $[-1,1]$ 'registering the intensity of expressive feeling that $a$ has towards $b$ as well as its degree of positivity or negativity. The narrower the interval, the more intense the feelings; the more negative the interval, the more negative the feelings (and conversely)' (Potts 2007b, 256). In other words, whenever a speaker uses an expressive we can represent their (or the relevant judge's) heightened emotional state towards some entity. For example, If Frank hates Nirvana he might utter:

(1) That damn Nirvana are playing again.

We could represent this in the following way: $<[[$ Frank] $][-.9,-1]$ [[Nirvana $]]>$. Expressive morphemes only affect the expressive index, meaning that no contribution to the propositional content at issue in an utterance of the sentence has been provided. Thus (1) conveys two different types of contents: descriptive 'Nirvana are playing again', and expressive 'Frank hates Nirvana', where only the descriptive content contributes to the truth-conditions of (1). 
Potts claims that a satisfactory semantics for expressives must account for six characteristics of expressive content: independence, nondisplaceability, perspective dependence, descriptive ineffability, immediacy, and repeatability. We briefly explain each below for the sake of completeness but will focus on only some of these when assessing the prospects for relativism.

\section{Independence.}

Expressive meaning and descriptive meaning operate independently of one another: removal of the expressive from the proposition leaves the descriptive content unchanged (Potts 2007a, 168). For example. 'Nirvana are playing again' has exactly the same descriptive meaning/truth-conditions as 'That damn Nirvana are playing again'.

\section{Nondisplaceability.}

'[E]xpressives cannot (outside direct quotation) be used to report on past events, attitudes, or emotions, nor can they express mere possibilities, conjectures, or suppositions' (ibid., 169). In other words, the expressive content of an utterance is always fixed to the context of that utterance. Expressives are wholly resistant to any context-shifting operation, remaining fixed to the context of utterance in all uses apart from those employing metalinguistic operators (e.g. quotation).

\section{Perspective dependence.}

Expressive content always encodes the perspective of a contextually fixed judge. Most commonly this is the agent of the context. However, the fact that speakers can seem to express attitudes distinct from their own demonstrates that the perspective encoded need not be the speaker's.

Descriptive ineffability. Speakers are commonly unable to paraphrase the expressive content of their speech into propositional content. If, for example, one were to say 'John is a fuckhead', there doesn't seem to be a descriptive paraphrase available that conveys all of the content of the expressive. Of course, we could produce a partial 
paraphrase such as 'John is not a nice/capable person', but this misses the expressive power that the word 'fuckhead' has. ${ }^{4}$

\section{Immediacy.}

An utterance of an expressive imposes its contribution onto the context of utterance immediately. The expressive content cannot be cancelled or denied. The very utterance of an expressive impacts on the expressive index to alter the context immediately.

\section{Repeatability.}

When an expressive is repeated within the same context it increases the degree to which the heightened emotional state of the judge is expressed. For example, the addition of expressive content to 'Philip stole my wallet', seen in 'Philip stole my fucking wallet', can be increased by adding further expressive items: 'Philip fucking stole my fucking wallet', 'Fucking Philip fucking stole my fucking wallet'. The additional expressives increase the anger expressed. This is contrary to the behaviour of truth-conditional content, for which repetition is redundant.

Each of the above features can be explained straightforwardly by Potts's semantics as each can be naturally understood as a consequence of an expressive's meaning being a matter of its impact on the expressive index of the context of utterance. We now turn to Lasersohn's proposed relativist account which seeks to capture the subjective and perspectival aspect of expressive content.

\section{2: Lasersohn's Alternative Account: Semantic Relativism}

Lasersohn (2017) develops a semantic relativist theory primarily to account for predicates of personal taste (PPTs). PPTs are words expressing tastes like, 'tasty',

\footnotetext{
${ }^{4}$ Moreover, we can easily imagine a context where that sentence is uttered in an affectionate way. Potts gives the example of an advert for a T-shirt emblazoned with the slogan: 'Here's To You, Ya bastard!', which continues: 'You've been such a good friend to me through the years. I'm so grateful' (Potts 2007a, 177). Potts also notes that expressives need not be restricted to human targets (Ibid.), thus if I hit my knee on the desk there's no reason why I can't call my desk a 'fucker' to express frustration and annoyance.
} 
'fun', 'funny', etc. Most notably they appear to give rise to faultless disagreement, as demonstrated below:

\section{(2) A: Falafels are tasty \\ B: Falafels are not tasty}

Here we have a disagreement as two contradictory propositions are expressed ${ }^{5}$. However, we do not feel comfortable in saying that either speaker has expressed a false proposition; neither speaker is at fault.

To account for PPTs and faultless disagreement, Lasersohn introduces a judge parameter into the circumstance of evaluation. The circumstance of evaluation, it is important to note, is not the same as the context of utterance. Contexts of utterance provide parameters for context-sensitive terms which must be saturated before a propositional content is expressed. Circumstances of evaluation, on the other hand, are the points at which a previously fixed semantic content is evaluated. Following Kaplan (1989), circumstances of evaluation are traditionally construed as world/time pairs. A proposition is true relative to a world and a time. Introducing judges into circumstances of evaluation allows us to extend the number of parameters that propositions are true or false relative to. Propositions, on this extended model, are true relative to a triple consisting of a world, time, and judge. Thus, we can say that, in (2), A's utterance is true relative to A as the judge, whereas B's utterance is true relative to $\mathrm{B}$ as the judge. Including the judge in the circumstance of evaluation allows us to keep the semantic content the same between both speakers. This is an important factor in accounting for the disagreement. For if the content of the propositions varied from A to B (as it would be if the content expressed were sensitive to a judge parameter in the context of utterance), then there would no longer be two contradictory propositions expressed and, therefore, no disagreement. The inclusion of a judge parameter in the circumstance of evaluation allows us to keep the semantic content

\footnotetext{
5 The claim that two contradictory propositions have been expressed is not unanimously accepted. Contextualists, for example, argue that no contradiction is present (or that no contradiction is needed to account for disagreement) in cases like (2). See, Cappelen and Hawthorne (2009), Stojanovic (2007), Sundell (2011) for discussion.
} 
the same across differing contexts of utterance whilst relativising the truth-values they may have to different circumstances.

Lasersohn $(2007,2017)$ suggests that the same analysis can be applied to expressives. Roughly, he proposes that whenever sentences containing expressives are uttered we should relativise the truths of the propositions expressed to the relevant judges. Lasersohn suggests that the truth conditions of (3a) are something like (3b) with (3a) differing just by virtue of carrying more of an 'emotional charge':

(3) (3a): John is an asshole.

(3b): John is obnoxious.

He goes on to say that 'there seems to be no objective way to classify people as obnoxious, let alone assholes' (Lasersohn, 2017: 233). This is a feature that PPTs seem to share with expressives: just like there are no objective facts in respect to whether falafels are tasty, there are also no objective facts in respect to whether people are assholes. Because there doesn't seem to be an objective way to classify people as assholes, we can locate faultless disagreements using expressives just as we see with PPTs:

(4) A: John is an asshole!

B: No, John is not an asshole!

This disagreement seems to be faultless in a similar way that disagreement over PPTs is, as 'ultimately, who counts as an asshole seems to depend on our tastes in human behaviour' (ibid.). Derogatory epithets are in some sense matters of personal tastes on this account. Thus, A and B would have both uttered something true relative to circumstances of evaluation where they featured as the relevant judges.

Before evaluating Lasersohn's relativistic account of expressives it will be instructive to contrast it with Potts's account. A fundamental difference between Potts's account and Lasersohn's account concerns the placement of the judge parameter. Despite the superficial similarity that their shared use of the judge parameter might suggest, this notion plays a very different and, we will see, mutually incompatible, role in each theory. As we saw, for Potts the judge parameter belongs in the context of utterance and plays a direct role in influencing the expressive index 
within that context. For Lasersohn, the judge parameter is placed in the circumstance of evaluation, where the propositional content is assessed. This highlights two major differences between the two accounts. Firstly, Potts's account treats the judge parameter along the same lines as the parametric settings of context required for indexical elements. The result is that expressive content is sensitive to the context of utterance in just the same way as indexical content and different utterances of the same expressive sentence can differ in content. Lasersohn's theory, by contrast, is designed to avoid this result and provide context insensitive propositions. which are thus subject to evaluations which may differ, depending on the circumstance of evaluation. Secondly, Potts's insistence that expressives directly modify an expressive index independently of the descriptive content expressed by the utterance entails that the expressive content of an utterance is distinct from its propositional content. Lasersohn, by contrast, requires the expressive content to be propositional in order to assign relativistic truth-values to propositions containing expressives. Only that which is propositional can be true or false, and only that which can be true or false can be relatively true or false.

\section{Context-Sensitive Content Versus Relative Truth.}

In this section, we commence our criticisms of Lasersohn's relativistic approach to expressives. The criticisms will question whether an account of expressive content modelled on a relativist semantics provides as compelling an account as one which treats expressive content as a context-sensitive element of content as, for example, Potts (2007a) does. We aim to show that there are core aspects of expressive meaning demanding that we treat it as context-sensitive, hence the context-invariant contents demanded for a relativist semantics will be inadequate for a semantic analysis of expressives.

\subsection{Stability of Content and Disagreement.}

We start by discussing Lasersohn's 'stability of content' argument, through which he seeks to establish that a relativistic treatment of expressives is required to account for the feeling of faultless disagreement we see in (5): 
(5) A: John is an asshole.

B: No, John is not an asshole.

Parallel to PPTs, we get disagreement because two contradictory propositions are expressed. Given that there is no objective property of being an 'asshole', we want to say that neither A nor B have uttered anything false. Accordingly, the disagreement seems faultless.

Lasersohn suggests that we need to have stability of content across A's and B's utterances to account for the disagreement. This leads him to say that we need to relativise the truth-value, not the content, thus we need to locate the judge parameter in the circumstance of evaluation. If we did take the judge parameter to be part of the context, then we would be left with 'an undesirable side effect, namely that expressives express different content relative to different individuals' (Lasersohn 2007,226 , original emphasis). This effectively means that (5) would equate to $\left(5^{*}\right)$ :

$\left(5^{*}\right)$ A: John is an asshole 1 .

B: John is not an asshole 2 .

Where 'asshole $\mathrm{n}_{\mathrm{n}}$ ' has a variable content that reflects the judgement of the speaker. In other words, when A and B use the term 'asshole' they are not really talking about the same thing: 'asshole ${ }_{1}$ ' and 'asshole 2 ' differ in content, leaving A and B 'speaking past' one another. According to Lasersohn, if expressive content did function in this manner, the two propositions expressed would no longer be contradictory and $\left(5^{*}\right)$ would be lacking in disagreement. Consequently, we would no longer be able to account for the faultless disagreement apparently present in (5). As we saw, this is the same motivation for introducing judge parameters into circumstances when evaluating PPTs.

One thing to notice before proceeding further to consider criticisms of Lasersohn's theory as an account of expressive content is that it is not at all clear that we do need stability of content in order to account for the disagreement present in cases like (5). Lasersohn presupposes a narrow conception of disagreement, where the disagreement is due to the propositional content of the expressions uttered. This is evident from his insistence that a contradiction is expressed in cases like (5). This insistence, however, is unjustified. Sundell (2011) shows that there are many different 
types of disagreement, some of which are non-propositional. For example, we might have 'implicature disagreement':

(6) (a) Gary ate some crackers and went to bed.

(b) Nuh uh, he went to bed and ate some crackers.

(Sundell 2011, 275) ${ }^{6}$

In (6), the speakers are not disagreeing over the literal content of the propositions expressed (as the semantic content is identical in both utterances), rather the object of their disagreement is the conversationally implicated temporal order of events produced by the connective 'and'. We can clearly see that although there is no contradiction over the literal propositional content, disagreement is still present.

Examples like (6), give us reason to consider a wider range of disagreements that we might encounter - especially ones that do not rely on literally expressed propositional content. We saw that for Potts expressives do not carry descriptive content, thus whatever disagreement is present in (5) cannot have anything to do with contradicting propositional content on his view. If we shift our focus from the narrow conception of disagreement as demanded by Lasersohn, to non-propositional disagreements as exemplified by (6), then we have good reason to account for disagreements like (5) within Potts' non-propositional framework.

Potts is in a comfortable position to explain the disagreement in (5). When A and B disagree over whether John is an asshole, we can see a difference in the interval of the expressive indices. If A's and B's intervals are completely 'disjoint, then we have a clear-cut disagreement' (Potts 2007b, 258). We can see that in (5) the intervals are disjoint, A's interval is narrower and more negative in degree, whereas B's interval is more positive. The disagreement is not over whether the content of the proposition is true or false, but rather about whether the intensity of the expressive index is appropriate ${ }^{7}$.

\footnotetext{
${ }^{6}$ For more examples of non-propositional disagreements see Sundell (2011, 275-279). 7It seems clear that there are close similarities between Potts' theory and contextualist accounts of PPTs as discussed in footnote 5. In the sense that Potts denies that contradiction is required to explain disagreement. Exploring this similarity further is beyond the scope of this paper.
} 


\subsection{Expressive Punch}

Perhaps the most significant obstacle to any attempt to accommodate expressive content within a relativist framework is the problem of reconciling the demand, essential to relativism, for a stable content shared between speakers, and the intuition that expressives conventionally encode information that is highly sensitive to the speaker's (or other judge's) emotional state, attitudes and viewpoints. Especially in perspective shifting examples, more of which are discussed below, Potts (2007a) takes the fact that expressives encode the perspective of a contextually provided judge to be a fundamental feature of expressive content. Expressives reveal information about the emotional state of the speaker/judge. Furthermore, they do so by default, expressing this information in all standard contexts of use. If a speaker, on first hearing a song, says: 'Wow! This is awesome!', speakers of English sufficiently acquainted with the context of her utterance know immediately that she is in a heightened emotional state and has an extremely positive attitude towards the song. Clearly, the communication of this emotional state is a core function of expressives. The expressive 'Wow' is added to the description to strengthen the affirmation of the song's quality (as judged by the speaker). This judgement of quality is expressed by a PPT, of course, but that does not mean that the expressive element functions the same way as the PPT expression it modifies. Similarly, just because 'Yummy, this falafel is delicious' expresses a judgement of taste, it does not mean that the expressive contained in it has to be subsumed to the same analysis as the PPT 'delicious'. Indeed, it is hard to see how it can be making any contribution to the propositional content of the utterance. The truth-conditions of 'Yummy, this falafel is delicious', after all, seem to be identical to those of 'this falafel is delicious'.

As Potts notes, it appears crucial to this content that it resists paraphrase in non-expressive terms. This can be seen in Lasersohn's attempted paraphrase of 'John is an asshole' as 'John is obnoxious'. There may be a similarity in what is communicated by utterances of these two sentences, but the latter is lacking the former's ability to encode information concerning the speaker's emotional state or attitude. Lasersohn admits as much when he acknowledges that the first sentence has 'a stronger expressive punch' (Lasersohn 2017, 233) and that expressives are 'emotionally charged' (Lasersohn 2007, 228). But no account is offered of what this expressive punch amounts to and how it is incorporated into the content of the expressive. But this means that a defining semantic characteristics of expressives that 
distinguishes them from non-expressives - ineffability - is left unexplained on his account. Furthermore, so long as that account is restricted to an account given in terms of propositional content, it is hard to see what resources are available for the description of ineffability.

\subsection{Presupposition and Projection}

Lasersohn's strategy for attributing a propositional content to (at least some) expressives is to suggest that much of the data appealed to by Potts can be explained by assuming that the propositional content (or contribution to that content) of these terms is presuppositional. For example, the resistance of expressive content to negation in (7) is also displayed by the non-expressive term in (8), because we cannot negate the presupposition introduced in (8) (except by appeal to a metalinguistic reading of the negation):

(7) That asshole Philip didn't steal your bike. (*He's a great guy).

(8) Your best friend Philip didn't steal your bike. (*You don't like him).

The only way that presuppositions can be negated is by 'interrupting' the conversation, and challenging the presupposition explicitly (hence they can be revealed by the 'hey, hang on a minute' test - see Shanon 1976, von Fintel 2004):

(9) A: Your best friend Philip stole your bike.

B: Hold on - he isn't my friend!

Negation of the presupposition, and the expressive, requires something more than straightforward negation.

However, there are key differences between presupposition and expressive content as construed by Potts. In particular, Potts holds expressive content to always project. Projection is the property of being immune to any operators that would shift the expressive content away from the perspective of the judge. On Potts's account, we should expect the judge's emotional state to be expressed in all contexts of use and to be immune to any operators on that expressive content. If the function of an expressive is to encode the judge's emotional state or attitude then they will effectively function as a form of indexical, contributing this information about the 
judge in all contexts of use. This means that they will not fall within the scope of operators such as propositional attitude verbs. Thus, expressives project their content into wide scope with respect to such operators, and cannot be embedded under them (excluding metalinguistic operators like quotation, as we see with indexicals):

(10) That damn Nirvana are playing again

(11) John believes that damn Nirvana are playing again.

(12) John said 'that damn Nirvana are playing again'.

In (10) the speaker transparently expresses her negative evaluation of Nirvana. In (11) she reports John's negative evaluation of Nirvana, but the expressive dimension of the report is attributable to her. For example, if one found such expressions of dislike unduly vulgar, it would be inappropriate to chastise John for his belief - the expression of the belief is what was deemed vulgar and hence the speaker of (11) merits chastisement. This is not the case in (12) where the metalinguistic operator does force the expressive content of 'damn' into narrow scope, thus not attributing any vulgarity to the speaker.

There are interesting borderline cases where the metalinguistic operation fails (or fails to be recognized). A recent example involved the sacking of an executive for Netflix who offended colleagues by mentioning the $\mathrm{N}$-word during meetings. The justification for sacking the executive provided by the head of the company was that, given the widely accepted euphemistic term 'the N-word' to denote the offensive pejorative term there was no justification for even mentioning the actual word in question:

There is not a way to neutralize the emotion and history behind the word in any context. The use of the phrase 'N-word' was created as a euphemism, and the norm, with the intention of providing an acceptable replacement and moving people away from using the specific word.

When a person violates this norm, it creates resentment, intense frustration, and great offense for many.

(Cited in Tapper 2018) 
Whether the example demonstrates a genuine failure of quotation to block projection of the derogatory content is unclear. A more likely explanation is that the explosive impact of this particular expressive makes it especially important to ensure that mention is not mistaken for use, and that the adoption of a special 'mentioning' term (the $\mathrm{N}$-word) is becoming a socially accepted norm to facilitate this. Violating this norm thus becomes potentially offensive in its own right. As far as we know, there are no other cases of such strict regulation arising over the conventions for mentioning an expression.

The projection of expressive content is explained in Potts's theory by locating the judge parameter in the context of utterance, thereby making expressive content sensitive to the context of utterance. Relativism, we have seen, is diametrically opposed to this approach. Content is context-invariant and only evaluated from different perspectives for the relativist.

Lasersohn's strategy for interpreting expressive content as a perspectiveindependent propositional content, we have seen, is to seek to explain the available data by taking the propositional content of expressives to be presuppositional. However, presuppositions do not appear to project in the same situations as expressives. While they routinely do project, they can also be subject to plugs. For example:

(13) Frank believes that Zappa's dog is barking too loud.

(14) Frank believes that Zappa's bastard dog is barking too loud.

In both (13) and (14), the attitude verb 'believes' acts as a presuppositional plug. Presuppositional plugs are 'predicates which block off all presuppositions of the complement sentences' (Karttunen, 1973, 174), ${ }^{8}$ they prevent the presupposition from carrying over to the speaker of the sentence. Thus, the presupposition, 'Zappa owns a dog', only stands in relation to Frank in both instances; the speaker need not be committed to this. If expressives functioned like presuppositions, then we should expect the expressive content also to be plugged and not apply to the speaker. However, this is not the case. In (14), we see that the expressive content of 'bastard'

\footnotetext{
${ }^{8}$ It should be noted that Karttunen expressed some reservations about whether propositional attitude verbs are plugs $(1973,189)$.
} 
carries over to the speaker so that we interpret the sentence as communicating that the speaker has a negative attitude towards Zappa's dog.

To defend relativism for expressives by appeal to a reduction of expressive content to presuppositional content for the relevant expressive terms, Lasersohn must provide an explanation for this apparent difference in respect to projection over plugs. His approach is twofold. Firstly, he seeks to challenge the assumption that expressive content always projects by providing examples that are alleged to demonstrate plugging of expressive content; secondly, he seeks to explain why projection is the default behaviour of expressives, by appeal to extra-linguistic considerations, thus arguing that the projection data does not reveal any irreducibly linguistic difference between expressive and presuppositional content.

He begins by offering an example intended to demonstrate that expressive content, like presuppositions, can be filtered. A presupposition filter, as defined by Karttunen $(1973,174)$ is a predicate which allows presuppositions to project only under certain conditions, blocking them when these conditions are not met. The example Lasersohn considers is 'if' which filters the presuppositions of its consequent clause, allowing them to project unless they are implied by the antecedent clause: If my professor uses tired old examples about wife-beating in his lectures, I will challenge him about his use of sexist stereotypes.

(16) If my professor comes to my birthday party, I will challenge him about his use of sexist stereotypes.

(16) presupposes that the speaker's professor uses sexist stereotypes; (15) does not, despite the presence of the presupposition in the consequent - it is only activated if the antecedent obtains. Lasersohn offers the following as evidence that expressive content is subject to the same filtering effects: 'I consider John a saint. But if he ever screws me over, I'll crush the bastard like a bug!' (Lasersohn 2007, 227). The expressive content of 'bastard' does not project up to the sentence as a whole (we already know from the previous sentence, after all, that the speaker thinks John is a 'saint', not a bastard, and there is no contradiction in the conditionalized 
continuation). Lasersohn also thinks that we can find examples where expressive content is plugged. He offers the following:

(17) Can you believe how unfairly Mary has reacted to John? He's a saint, really, but she practically exploded at him, and after he left, she went into this long rant about how she would kill the bastard.

(Lasersohn 2007, 228).

It is not at all clear that this is a compelling example, in our view. Lasersohn (ibid., 227) himself admits that 'it is harder to construct examples in which expressive content fails to project past believe or other plugs' than it is to find examples of filters. The example seems to show that this is an understatement. No example is given by him of a case where expressive content is plugged by 'believe'. The only example we have invokes 'rant' as a plug. But rants are speech acts, and to rant is to say certain things in certain ways. Thus, given the resistance of expressive content to plugs like 'believes', it is highly likely that the plugging effect here is due to an implicitly quotational reading of the speaker's utterance as meaning something akin to:

(18) Can you believe how unfairly Mary has reacted to John? He's a saint, really, but she practically exploded at him, and after he left, she went into this long rant about how she would "kill the bastard".

Furthermore, even if one is persuaded by the example that plugging of expressive content is possible, Lasersohn's presuppositional analysis faces two further serious problems:

(1) a convincing account of why expressives project past plugs by default, unlike normal presuppositions, is needed; (2) account for the apparent projection failure. Thus, Lasersohn's account of why expressive content projects past plugs by default needs to be more convincing than Potts's account of why these apparent cases fail to project, if the data Lasersohn appeals to is going to provide him with a compelling case for his theory. As we will explain below Potts actually denies projection failure 
for expressives, explaining this apparent data by appeal to a distinct mechanism. We will address (1) before turning to this.

Lasersohn's explanation for why expressive content is so rarely plugged takes as a starting point Karttunen's observation that 'all plugs are leaky' $(1973,175)$. He then notes that the consequences of a leaking plug of expressive material can impose substantial social risk on speakers. If I seek to report my colleague's negative evaluation of my manager using expressive terms to encode the colleague's attitude towards the manager (an attitude I do not share), it would be socially awkward for me, to say the least, if a leaking plug of the expressive content led listeners to attribute the expressive content of the expression of those attitudes to me instead of my colleague.

It is important to note that Karttunen's position was that plugs leak only in special cases. The default is that they do not leak. But, in the case of expressive content, we see the reverse: projection is the norm; plugs are rare in the extreme. Thus, it would seem that the only available explanation here would be that what makes these cases special is that they involve expressive content. But that surely means that expressives carry a feature or set of features which are lacking in presuppositions, and it is very hard to see how this can be consistent with any theory which seeks to reduce the content of expressives to presuppositions. Perhaps this is why Lasersohn is forced into the 'social risk' argument: it is simply not open to him to appeal to a linguistic feature of expressives that would make them special cases if he wants to reduce the content of an expressive to that of a presupposition (which is not special in this sense). This in turn, however, places an apparently intolerable demand on his account. For surely the only explanation available for this social risk has to rest on the identification of some feature which marks expressives out as special compared to other linguistic items. Indeed, Lasersohn does not manage to avoid appeal to features unique to the semantic profile of expressives when appealing to the social risk incurred by their use:

Because expressives are so emotionally charged, and because their use can carry a significant social risk, I suspect that speakers are especially cautious about using them in embedded contexts where there is a chance of their content "leaking" ... This, I suspect, is the correct explanation for why expressive content normally projects, rather than any theoretical distinction between presupposed and expressive content. 
(Lasersohn 2007, 228)

As we have seen above, features like emotional charge or expressive punch are central to the semantic profile of expressives. It is thus circular for Lasersohn to appeal to such features as a way of marking out expressives as special cases of presuppositions which can escape plugs - this feature of expressives $i s$ tracking a theoretical distinction between presupposed and expressive content. Presuppositions lack it, which is why they are normally affected by plugs; expressives have it, which is why they normally project beyond them. That does not mark expressive content as a special kind of presuppositional content - it marks it as distinct from presuppositional content.

We turn, finally, to (2): Lasersohn assumes that a demonstration that expressives do not always project will lend credence to the assimilation of expressive content to presuppositional content. However, this overlooks the fact that it is just these sorts of cases that motivates Potts to incorporate a judge parameter into his semantic theory in the first place. Potts denies that they are cases of projection failure, taking the examples instead to demonstrate that expressives are subject to a distinct mechanism facilitating perspective shifts

The precise details of the mechanism facilitating perspective shifts away from the speaker-oriented default, as well as extensive data in support of the need to accommodate such shifts, is provided in Harris and Potts (2009). Harris and Potts argue that the range of cases where non-speaker-oriented readings of expressive content are found suggests that perspective shifts are pragmatically mediated rather than being reliant on semantic binding by attitude predicates (which would demand a shiftable interpretation of expressives along the lines of Schlenker 2007). Whatever the preferred details of this mechanism, there is good evidence that it differs, at least in its results, from the mechanism which selects the relevant judge/perspective in uses of PPTs: Hess (2018: 19) provides examples which show clearly that the default perspective setting for PPTs in ordinary reports is opposite in the two cases, selecting the speaker in cases using expressives, and the reported agent for PPTs. Hess provides the following example to illustrate this point: 
a. Jim said that he ate some tasty Brussels sprouts again.

b. Jim said that he ate some damn Brussels sprouts again.

(Hess, 2018: 19, original emphasis)

In the case using a PPT we see that 'tasty' is interpreted as expressing Jim's tastes, whereas 'damn' (as predicted) expresses the attitude of the speaker and not $\mathrm{Jim}^{9}$.

A number of cases where expressives seem to undergo perspective shifts have been pointed out in the literature. A much-discussed example comes from Schlenker (2003, 98):

(19) I am not prejudiced against Caucasians. But John, who is, thinks/claims that you are the worst honky he knows.

Another, repeated here from section 1, comes from Kratzer (1999):

(20) My father screamed that he would never allow me to marry that bastard Webster.

In each case, the expressive content does not seem to encode the perspective of the speaker. ${ }^{10}$ We do not attribute racial prejudice to the speaker of Schlenker's example (the speaker has already clarified their lack of prejudice it seems), nor do we take 'bastard' to encode the speaker's attitude to Webster in Kratzer's example, as something about the construction makes it plain that this is expressing the father's attitude. $^{11}$

\footnotetext{
${ }^{9}$ We would like to thank an anonymous reviewer for bringing this point to our attention.

${ }^{10}$ Not everyone agrees that these examples really are compelling. Some might share Predelli's $(2013,106-107)$ suspicion that there is an air of implicit quotation in such examples. However, given that many (including both Potts and Lasersohn) do seem to find the examples compelling, we will not pursue doubts about such cases in this paper.

${ }^{11}$ Admittedly, Lasersohn (2017: 233, ft. nt. 16) excludes racial pejoratives from his theory so we will not attach too much importance to Schlenker's example here, but we mention it all the same to illustrate Potts's recognition that in
} 
Potts's approach is, of course, to appeal to the judge parameter in the context of utterance. The examples above make plain, according to Potts, that judges and speakers require distinct parameters. The identification of speaker and judge is simply a 'pragmatic default' (Potts 2007, 175). Without any cues to direct us otherwise, we automatically interpret an utterance of an expressive by an agent as expressing the attitude of the speaker.

But the fact that they can come apart, as in the examples above, and, indeed, as may be in the case of the examples offered by Lasersohn discussed above, demonstrates that the perspective encoded by the expressive and that of the agent of the utterance, need not coincide. When the context makes an alternative perspective to that of the speaker salient, the pragmatic default can be overridden. Semantically, this means that the judge parameter cannot be identified with the agent parameter. Potts notes that judges serve a similar role in Lasersohn's relativist framework. There are cases where speakers express judgements of taste which are not their own. These 'exocentric' uses as Lasersohn $(2017,142)$ calls them are cases where the judge parameter and speaker diverge in a way that is facilitated by contextual cues. So, for example, when Sally utters the sentence Real Ale is superior in taste to Lager in her role as publicity officer for CAMRA (Campaign for Real Ale), this may be true relative to a circumstance in which CAMRA is the judge while Sally herself finds the lukewarm, flat, and overly bitter-tasting drink that she is paid to endorse, quite repugnant.

Of course, we have seen that Lasersohn rejects the addition of a judge parameter into the context of utterance, as opposed to circumstance of evaluation, on the grounds that this treats expressives as making indexical reference to elements of context and thus denying that there is a context-invariant content shared in disagreement between speakers. But this has no bearing on the issue of explaining conditions under which expressive content can undergo perspective shifts and the explanation for why those conditions are rare. What needs explaining is why one perspective is privileged as the default for the interpretation of expressive content. By including a judge parameter into the contexts that expressives are paired with, Potts is able to explain the shifting of perspective under contextually mandated conditions for expressives in a way that is parallel to Lasersohn explanation of the evaluation of specifically seeks to accommodate this in his semantic theory. 
judgements of taste. But because the latter requires a context-invariant propositional content before the judge parameter can play a role, Lasersohn's model requires us to contort expressive content into a propositional form, hence the assimilation to presupposition. But, as we have seen, presupposition just does not behave the same way as expressive content with respect to projection. The role of the judge in Potts's semantics explains the projection-by-default of expressive content while accommodating the possibility of perspective shift in special cases. By the time that expressive content has been assimilated to presuppositional content in Lasersohn's theory it is, literally, too late for the judge to help: the judge is needed to determine the content, not to evaluate it.

\section{Conclusion}

In this paper, we have demonstrated that expressive content cannot be understood on the same model as Lasersohn's relativistic model for PPTs. Derogatory epithets, despite their superficial similarity with PPTs, therefore cannot be reduced to them so long as we accept that they carry an expressive content. Our points may be summarised as follows. As seen in section 2.1, disagreements involving expressives do not operate at the level of descriptive content. Section 2.2 demonstrated that Lasersohn's theory lacks the resources to explain the emotional/attitudinal content of expressives. Finally, in section 2.3, we provided arguments against Lasersohn's claim that expressive content can be understood as presuppositional.

Although our target in this paper has been narrow, namely Lasersohn's proposal, we take it to illustrate a point of wider significance. While both expressives and PPTs, are clearly subjective to some extent on close examination the way in which this subjectivity is manifested is very different. The subjectivity of expressive content demands the presence of the judge parameter in the context of utterance. The subjectivity of PPTs demands that the judge parameter be reserved for the circumstance of evaluation. $^{12}$

12 We would like to thank an anonymous reviewer for their helpful comments. 
Forthcoming in Inquiry (final draft manuscript of submitted version) 23 


\section{References}

von Fintel, K., 2004 'Would you believe it? The King of France is back! (Presuppositions and truth-value intuitions)' in A. Bezuidenhout \& M. Reimer (eds.), Descriptions and Beyond: An Interdisciplinary Collection of Essays on Definite and Indefinite Descriptions and other Related Phenomena, Oxford: Oxford University Press: $315-341$.

Harris, J. A., Potts, C., (2009), 'Perspective-shifting With Appositives and Expressives', Linguistics and Philosophy, 32(6): 523- 552.

Hess, L., 2018, 'Perspectival Expressives', Journal of Pragmatics, 129: 13-33.

Hu, X., 2018, 'The Epistemic Account of Faultless Disagreement', Synthese: 1-18.

Kaplan, D., 1989, 'Demonstratives: An Essay on the Semantics, Logic, Metaphysics, and Epistemology of Demonstratives and Other Indexicals', in J. Almog, J. Perry, H. Wettstein, (eds.), Themes from Kaplan, 1989, Oxford: Oxford University Press.

Karttunen, L., 1973, 'Presuppositions of Compound Sentences', Linguistic Inquiry, 4(2):169-193.

Kölbel, M., 2004, 'III-Faultless disagreement' Proceedings of the Aristotelian Society, 104(1): 53-73.

Kratzer, A., 1999, 'Beyond 'ouch' and 'oops': How descriptive and expressive meanings interact', Paper presented at the Cornell conference on theories of context dependency. Hand out available:

https://semanticsarchive.net/Archive/WEwNGUyO/Beyond\%20\%22Ouch\%22\%20a nd\%20\%22Oops\%22.pdf

Lasersohn, P., 2007, 'Expressives, Perspective and Presupposition', Theoretical Linguistics, 33(2): 223-230. 
Lasersohn, P., 2017, Subjectivity and Perspective in Truth-Theoretic Semantics, Oxford: Oxford University Press.

MacFarlane, J., 2014, Assessment sensitivity: Relative truth and its applications, Oxford: Oxford University Press.

Palmira, M., 2015, 'The Semantic Significance of Faultless Disagreement', Pacific Philosophical Quarterly, 96(3): 49-371.

Potts. C., 2005, Logic of Conventional Implicatures, Oxford: Oxford University Press.

Potts, C., 2007a, 'The Expressive Dimension', Theoretical Linguistics, 33(2): 165 198.

Potts, C., 2007b, 'The Centrality of Expressive Indices, Theoretical Linguistics, 33(2): 255-268.

Predelli, S., 2013, Meaning Without Truth, Oxford: Oxford University Press.

Schlenker, P., 2003, ‘A Plea for Monsters', Linguistics and Philosophy, 26(1), pp. 29120.

Schlenker, P., 2007, 'Expressive Presuppositions', Theoretical Linguistics, 33(2): 237-245.

Shanon, B., 1976, 'On the two kinds of presupposition in natural language', Foundations of Natural Language 14(2): 247-249.

Stojanovic, I., 2007, ‘Talking About Taste: Disagreement, Implicit Arguments, and Relative Truth', Linguistics and Philosophy, 30(6): 691-706.

Sundell, T., 2011, 'Disagreements About Taste', Philosophical Studies, 155(2): 267288. 
Forthcoming in Inquiry (final draft manuscript of submitted version) 26

Tapper, J., 2018. 'Netflix boss apologises to staff after executive sacked over Nword', $23^{\text {rd }}$ June 2018, The Observer, The Guardian Online

https://www.theguardian.com/media/2018/jun/22/netflix-chief-of-communicationsleaving-after-reports-of-using-n-word. Accessed 2018. 